Jurnal Care Vol .5, No.3,Tahun 2017

\title{
KETERKAITAN KARAKTERISTIK KELUARGA DENGAN PERSONAL HYGIENE ANAK SEKOLAH DASAR
}

\author{
Verarica Silalahi ${ }^{1}$, Ronasari Mahaji Putri ${ }^{2}$ \\ ${ }^{1,2)}$ Program Studi Ilmu Keperawatan Universitas Tribhuwana Tunggadewi \\ e-mail: putrirona@gmail.com
}

\begin{abstract}
There are still many people who do not pay attention to personal bygiene. In school-aged children, personal hygiene plays an important role. Family characteristics play a major role in establishing the habit of applying personal bygiene to school-aged children. Relationship family characteristics and personal bygiene in primary school children become determined this research. . The study design was cross sectional. The sample was 100 people (total sampling) of grade 3 to 5 in SD Negeri Merjosari 3. Personal bygiene data was taken based on direct observation, while the family characteristic data was taken from school profile data. Data were tested using Chi Square. Results found that there is a relationship between parent education (father and mother) with personal bygiene, and there is no correlation parent job (father and mother) with personal bygiene. The need for health education in the form of health promotion on personal hygiene to parents, especially mothers, to increase knowledge about personal hygiene.
\end{abstract}

Keywords: Family Characteristics, Primary School Children, Personal hygiene

\begin{abstract}
ABSTRAK
Masih banyak orang yang tidak memperhatikan personal bygiene. Pada anak usia sekolah, personal bygiene memegang peranan penting. Karakteristik keluarga berperan besar dalam pembentukan kebiasaan penerapan personal bygiene pada anak usia sekolah.Tujuan dilakukannya penlitian untuk melihat hubungan karakteristik keluarga dengan personal hygiene pada anak sekolah dasar. Riset observasioanl berdesain crosssectional. Besar sampel sebanyak 100 orang (total sampling) kelas 3 sampai kelas 5 yang ada di SD Negeri Merjosari 3. Data personal bygiene diambil berdasarkan pengamatan langsung sedangkan data karakteristik keluarga diambil dari data profil sekolah. Data diuji dengan ChiSquare. Hasil diketahui pendidikan orang tua (ayah dan ibu) berhubungan dengan variable personal bygiene $(\mathrm{p}<0,05)$, dan tidak terdapat hubungan antara pekerjaan orang tua (ayah dan ibu) dengan personal bygiene $(\mathrm{p}>0,05)$. Direkomendasikan perlunya pendidikan kesehatan berupa promosi kesehatan mengenai personal bygiene kepada para orang tua, khususnya ibu untuk meningkatkan pengetahuan tentang personal bygiene .
\end{abstract}

Kata Kunci : Anak Sekolah Dasar, Karakteristik keluarga,Personal bygiene 
Jurnal Care Vol .5, No.3,Tahun 2017

\section{PENDAHULUAN}

Masih banyak orang yang tidak memperhatikan personal bygiene karena halhal seperti ini sangat tergantung dari kebiasaan seseorang (Perry dan Potter, 2010). Personal hygiene anak yang tidak buruk menekan pintu masuk mikroorganisme sehingga mencegah seseorang untuk terkena penyakit (Saryono, 2010) sedangkan personal hygiene yang buruk akan mempermudah seseorang terkena penyakit yang berhubungan dengan personal bygiene, seperti penyakit infeksi, penyakit mulut dan gigi, kulit (skabies), dan penyakit saluran cerna atau menghilangkan sebagian fungsi bagian tubuh bagian tertentu, seperti kulit (Sudarto, 1996; Perry dan Potter, 2010).

Penelitian Ummah dan Lidiawati (2015) menemukan bahwa ada hubungan personal bygiene dengan tindakan pencegahan penularan penyakit kusta. Personal bygiene yang baik dapat mencegah bau tidak sedap dan menimbulkan rasa nyaman pada remaja yang sedang menstruasi (Yusiana dan Saputri, 2016) sedangkan personal bygiene yang tidak baik dapat menimbulkan kanker rahim, keputihan dan mengurangi aktivitas sehari-hari saat menstruasi (Indriastuti, 2009).

Personal bygiene juga berhubungan dengan kejadian skabies (Akmal et al., 2013). Penelitian Ramadhan dan Sabrina K.A (2016) menemukan bahwa ada hubungan antara personal bygiene dengan citra tubuh pada lansia. Lebih lanjut, peneliti menemukan bahwa responden yang memiliki personal bygiene kurang memiliki citra tubuh negatif sedangkan responden yang personal bygiene baik memiliki citra tubuh yang positif.

Personal bygiene berupa kebiasaan cuci tangan sebelum makan, kebiasaan cuci tangan setelah Buang Air Besar (BAB), dan kebiasaan jajan berhubungan dengan kejadian demam tifoid pada anak (Karim et al., 2014). Hiola (2012), ada pertalian yang bermakna kebersihan kulit kepala,rambut dengan kejadian penyakit kulit. Berdasarkan penelitian Sajida (2012), terdapat hubungan yang bermakna antara kebersihan tangan, kaki, dan kuku terhadap keluhan penyakit kulit di Masyarakat Kelurahan Denai. Berdasarkan penelitian Faridawati (2013), ada hubungan yang bermakna antara 
kebersihan kulit dengan keluhan gangguan kulit. Berdasarkan penelitian Kusnin (2015), kebersihan tangan, kaki dan kuku berhubungan dengan penyakit kulit.Arikan et al. (2014) menemukan bahwa siswa dengan kebersihan yang buruk meningkat pada golongan kelompok ibu yang memiliki tingkat pendidikan rendah dan pendapatan keluarga yang rendah. Selain itu, frekuensi siswa yang memiliki kebersihan yang buruk lebih tinggi pada siswa laki-laki. Penelitian ini tidak menemukan hubungan antara personal bygiene dengan umur orang tua, kelompok umur siswa dan tingkat pendidikan ayah.

Pada anak usia sekolah, personal bygiene memegang peranan penting. Waktu bermain dan belajar yang dihabiskan selama berada di sekolah tidak menutup kemungkinan bagi kelompok usia ini menjadi jalan masuk bagi berbagai jenis penyakit atau masalah kesehatan lainnya. Selain itu, anak usia sekolah masih memerlukan perhatian mengenai pembentukan kebiasaan personal bygiene. Waktu yang dihabiskan selama di sekolah mengharuskan mereka melakukan aktivitas fisik yang tidak jarang menyebabkan masuknya kebiasaankebiasaan dari teman sebaya. Dalam menerapkan personal bygiene yang baik dan benar, mereka masih memerlukan dukungan dan motivasi dari keluarga sebagai tempat acuan mereka untuk berperilaku. Karakteristik keluarga berperan besar dalam pembentukan kebiasaan penerapan personal hygiene pada anak usia sekolah. Karakteristik keluarga terdiri dari usia orang tua, agama, suku, pekerjaan orang tua, pendidikan orang tua, pendapatan keluarga.

Hasil pengamatan langsung yang dilakukan di SD Negeri Merjosari 3 ditemukan siswa siswi yang memiliki masalah gigi berupa karies gigi, berpakaian tidak rapi, menggunakan kran air yang tersedia hanya untuk bermain air, dan melepaskan sepatu ketika berada di sekolah. Semua perilaku tersebut diketahui sebagai perilaku personal bygiene. Berdasarkan wawancara dari pihak sekolah ditemukan bahwa sikap dan perilaku siswa tersebut dikarenakan anak-anak tidak mengenal konsep personal bygiene yang baik dan benar. Faktor ketidaktahuan ini bisa berasal dari kurangnya penyebarluasan informasi mengenai konsep personal bygiene yang baik dan benar. Konsep personal bygiene yang lengkap belum pernah diberikan di sekolah ini, hanya penyuluhan tentang kesehatan gigi. Sementara itu, faktor 
Jurnal Care Vol .5, No.3,Tahun 2017

keluarga juga berperan penting dalam menyebarluaskan informasi tentang personal bygiene. Hal inilah yang mendasari perlunya dilakukan penelitian untuk melihat hubungan antara karakteristik keluarga dengan personal hygiene pada anak Sekolah Dasar Negeri Merjosari 3.

\section{METODE PENELITIAN}

Cross sectional desainnya. Penelitian berlokasi di SD Negeri Merjosari 3. Populasi pada penelitian ini adalah semua siswa siswi yang ada di SD Negeri Merjosari 3, mulai dari kelas 3 sampai 5, yaitu sebanyak 100 orang. Sampel penelitian adalah semua siswa siswi kelas 3 sampai 5, yaitu sebanyak 100 orang (total sampling). Variabel bebas yaitu karakteristik keluarga dan variabel terikat yaitu personal bygiene . Data karakteristik keluarga diambil berdasarkan data yang tersedia di buku profil SD Negeri Merjosari 3 sedangkan data personal bygiene diambil berdasarkan pengamatan langsung pada anak sekolah kelas 4 sampai 6. Data-data ini selanjutnya diolah menggunakan SPSS ver. 21. Data karakteristik keluarga (pendidikan, pekerjaan dan pendapatan) dan personal bygiene dianalisis menggunakan uji Chi square. Bila tidak memenuhi syarat, maka digunakan uji Fisher.

\section{HASIL}

Berdasarkan Tabel 1 dapat dilihat bahwa pekerjaan ayah terbanyak adalah karyawan swasta (37,0\%).Pekerjaan ibu terbanyak adalah tidak bekerja $(73,0 \%)$ dan tidak ada ibu yang bekerja sebagai supir $(0,0 \%)$. Pendidikan ayah terbanyak adalah SMA sederajat $(41,0 \%)$ dan paling sedikit adalah tidak sekolah (1,0\%). Pendidikan ibu terbanyak adalah SMA sederajat $(35,0 \%)$ dan tidak ada ibu yang tidak sekolah $(0,0 \%)$.

Berdasarkan Tabel 2 dapat dilihat bahwa 94\% siswa tidak hygiene .

Berdasarkan Tabel 3, dapat dilihat bahwa siswa dari ayah dengan tingkat pendidikan rendah lebih banyak yang tidak hygiene (96,6\%) dibandingkan siswa dari ayah dengan tingkat pendidikan tinggi (76,9\%). Siswa dari ibu dengan tingkat pendidikan rendah lebih banyak tidak hygiene $(97,6 \%)$ dibandingkan siswa dari ibu dengan tingkat pendidikan tinggi (76,5\%). Siswa dengan tingkat pekerjaan ayah rendah lebih banyak tidak hygiene $(98,2 \%)$ dibandingkan siswa dengan tingkat pekerjaan ayah tinggi 
$(88,9 \%)$. Siswa dengan tingkat pekerjaan ibu rendah juga lebih banyak tidak hygiene
(95,3\%) dibandingkan siswa dengan tingkat pekerjaan ibu tinggi (85,7\%).

Tabel 1. Distribusi Frekuensi Karakteristik Keluarga Anak Sekolah Dasar Merjosari 3

\begin{tabular}{|c|c|c|}
\hline Karakteristik & f & $\%$ \\
\hline \multicolumn{3}{|l|}{ Pekerjaan Ayah } \\
\hline $\begin{array}{l}\text { a. Pegawai Negeri Sipil/TNI/Polri } \\
\text { b. Buruh }\end{array}$ & 8 & 8,0 \\
\hline c. Wiraswasta & 14 & 14,0 \\
\hline d. Karyawan Swasta & 36 & 36,0 \\
\hline e. Supir & 37 & 37,0 \\
\hline \multirow[t]{2}{*}{ f. Tidak Bekerja } & 4 & 4,0 \\
\hline & 1 & 1,0 \\
\hline Total & 100 & 100,0 \\
\hline \multicolumn{3}{|l|}{ Pekerjaan Ibu } \\
\hline $\begin{array}{l}\text { a. Pegawai Negeri Sipil/TNI/Polri } \\
\text { b. Buruh }\end{array}$ & 3 & 3,0 \\
\hline c. Wiraswasta & 4 & 4,0 \\
\hline d. Karyawan Swasta & 9 & 9,0 \\
\hline e. Supir & 11 & 11,0 \\
\hline \multirow{2}{*}{ f. Tidak Bekerja } & 0 & 0,0 \\
\hline & 73 & 73,0 \\
\hline Total & 100 & 100,0 \\
\hline \multicolumn{3}{|l|}{ Pendidikan Ayah } \\
\hline a. Tidak Sekolah & 1 & 1,0 \\
\hline b. SD Sederajat & 20 & 20,0 \\
\hline c. SMP Sederajat & 25 & 25,0 \\
\hline d. SMA Sederajat & 41 & 41,0 \\
\hline e. Strata 1 & 11 & 11,0 \\
\hline f. Strata $2 /$ Strata 3 & 2 & 2,0 \\
\hline Total & 100 & 100,0 \\
\hline \multicolumn{3}{|l|}{ Pendidikan Ibu } \\
\hline a. Tidak Sekolah & 0 & 0,0 \\
\hline b. SD Sederajat & 22 & 22,0 \\
\hline c. SMP Sederajat & 26 & 26,0 \\
\hline d. SMA Sederajat & 35 & 35,0 \\
\hline e. Strata 1 & 15 & 15,0 \\
\hline f. Strata $2 /$ Strata 3 & 2 & 2,0 \\
\hline Total & 100 & 100,0 \\
\hline
\end{tabular}

Sumber data: Penelitian, 2017 
Jurnal Care Vol .5, No.3,Tahun 2017

Tabel 2. Distribusi Frekuensi Personal bygiene pada Siswa

\begin{tabular}{|l|r|r|}
\hline Personal hygiene & \multicolumn{1}{|c|}{ f } & \multicolumn{1}{|c|}{$\%$} \\
\hline Tidak Hygiene & 94 & 94,0 \\
Hygiene & 6 & 6,0 \\
\hline Total & 100 & 100,0 \\
\hline & & \\
\hline
\end{tabular}

Sumber data: Penelitian, 2017

Tabel 3. Hubungan Karakteristik Keluarga dengan Personal Hygiene Siswa

\begin{tabular}{|c|c|c|c|c|c|}
\hline \multirow[t]{2}{*}{ Karakteristik } & \multicolumn{2}{|c|}{$\begin{array}{c}\text { Tidak } \\
\text { Hygiene }\end{array}$} & \multicolumn{2}{|c|}{ Hygiene } & \multirow[t]{2}{*}{$p$} \\
\hline & $\mathbf{n}$ & $\%$ & $\mathbf{n}$ & $\%$ & \\
\hline \multicolumn{6}{|l|}{ Pendidikan Ayah } \\
\hline Rendah & 84 & 96,6 & 3 & 3,4 & $0,028^{*}$ \\
\hline Tinggi & 10 & 76,9 & 3 & 23,1 & \\
\hline \multicolumn{6}{|l|}{ Pendidikan Ibu } \\
\hline Rendah & 81 & 97,6 & 2 & 2,4 & $0,007^{*}$ \\
\hline Tinggi & 13 & 76,5 & 4 & 23,5 & \\
\hline \multicolumn{6}{|l|}{ Pekerjaan Ayah } \\
\hline Rendah & 54 & 98,2 & 1 & 1,8 & 0,088 \\
\hline Tinggi & 40 & 88,9 & 5 & 11,1 & \\
\hline \multicolumn{6}{|l|}{ Pekerjaan Ibu } \\
\hline Rendah & 82 & 95,3 & 4 & 4,7 & 0,197 \\
\hline Tinggi & 12 & 85,7 & 2 & 14,3 & \\
\hline
\end{tabular}

Hasil uji statistik membuktikan bahwa terdapat hubungan antara pendidikan ayah dengan personal bygiene $\quad(\mathrm{p}=0,028)$, terdapat hubungan antara pendidikan ibu dengan personal bygiene $(\mathrm{p}=0,007)$, tidak terdapat hubungan antara pekerjaan ayah dengan personal bygiene $(\mathrm{p}=0,088)$ dan tidak terdapat hubungan antara pekerjaan ibu dengan personal bygiene $(\mathrm{p}=0,197)$.

\section{Hubungan Pendidikan Orang Tua dengan Personal hygiene}

Pendidikan yang didapatkan seseorang semasa hidupnya erat kaitannya dengan pengetahuan yang dimiliki oleh orang tersebut. Dari pendidikan, maka akan terbentuk pengetahuan yang nantinya akan memengaruhi sikap dan tindakan seseorang terhadap sesuatu hal. Hasil menunjukkan bahwa antara personal hygiene dengan pendidikan orang tua terdapat hubungan. 
Jurnal Care Vol .5, No.3,Tahun 2017

$(p<0,05)$. Menurut Efendi dan Makhfudli (2009), keluarga, sebagai satu kesatuan, dipandang sebagai sumber daya kritis untuk menyampaikan pesan-pesan kesehatan. Anggota keluarga belajar tentang disiplin, norma-norma, budaya, dan perilaku melalui hubungan dan interaksi dalam keluarga. Fungsi keluarga sebagai health care function berguna dalam mempertahankan keadaan kesehatan keluarga agar tetap memiliki produktivias yang tinggi. Status individu dan keluarga dipengaruhi kemampuan perawatan keluarga . Keluarga biasanya menyediakan pakaian, perlindungan,makaan dan melakukan peeliharaan kesehatan. Tingkat pengetahuan keluarga tentang sehat-sakit juga memengaruhi perilaku keluarga dalam menyelesaikan masalah kesehatan keluarga.Menurut Hassan et al. (2002), lingkungan rumah berpengaruh besar dalam pertumbuhan dan perkembangan anak sehingga diperlukan bantuan yang aktif. Peranan orang tua diantaranya adalah berusaha mempelajari masalah kesehatan dan hal-hal yang didapat anaknya di sekolah serta menganjurkan dan mengawasi agar anaknya menjalankan kebiasaan hidup sehat.Lingkungan fisikobiopsikososial berupa pengetahuan keluarga mengenai kesehatan. Selain itu, seorang anak memperkaya jiwanya dengan permainan dan alat permainan, serta memperkaya pengetahuannya dengan mendengar, melihat dan bertanya. Pertumbuhan anak akan memuaskan bila ada hubungan yang baik antara ibu dan anak. Mendidik anak harus berarti memberikan pengertian tentang kebiasaan yang baik dan memperlakukannya dengan penuh kasih sayang. Hal demikian dapat dicapai dengan selalu memberikan contoh yang baik. Contoh yang diberikan orang tua mempunyai arti yang penting bagi anak. Dasar pendidikan untuk anak adalah membiasakan anak untuk melakukan sesuatu pada waktu-waktu tertentu dan teratur (Hassan et al, 2002).

Lebih lanjut, Notoatmodjo mengatakan bahwa masyarakat perlu diubah dalam berperilaku untuk hidup sehat yakni dengan megajak, membujuk, ataupun kegiatan lain yang dapat menyadarkan akan pentingnya berperilaku sehat, dan dapat ditempuh dengan pendidikan kesehatan. Perilaku seseorang tentang kesehatan ditentukan oleh pengetahuan, sikap, kepercayaan, tradisi dan sebagainya dari orang atau masyarakat yang bersangkutan sehingga dapat dikatakan bahwa seseorang tidak bygiene karena orang tersebut tidak tahu atau belum tahu manfaat menjaga 
kebersihan diri. Kurangnya pengetahuan orang tua dalam hal personal hygiene dapat dibenarkan berdasarkan hasil wawancara dengan pihak sekolah yang mengatakan bahwa belum pernah diadakannya penyuluhan mengenai personal bygiene, baik langsung kepada siswa maupun kepada orang tua. Padahal pendidikan kesehatan merupakan bentuk intervensi terhadap faktor perilaku.

\section{Hubungan Pekerjaan Orang Tua dengan Personal hygiene}

Pekerjaan erat kaitannya dengan status sosial ekonomi keluarga dalam masyarakat. Tidak terdapat hubungan antara pekerjaan orang tua dengan personal hygiene ( $\mathrm{p}>0,05)$. Hasil ini didukung oleh Notoatmodjo (2010) yang menyatakan bahwa orang tua, khususnya ibu, adalah faktor yang sangat penting dalam mewariskan status kesehatan kepada anakanak mereka. Rendahnya kesehatan orang tua, terutama ibu, bukan hanya karena sosial ekonominya rendah, tetapi juga sering disebabkan karena orang tua atau ibu tidak mengetahui bagaimana cara memelihara kesehatannya. Kurangnya pengetahuan orang tua didukung dari hasil penelitian ini yang menemukan masih rendahnya tingkat pendidikan orang tua, baik ayah maupun ibu.

\section{KESIMPULAN}

1. Pendidikan orang tua berkorelasi dengan personal hygiene $(\mathrm{p}<0,05)$.

2. Tidak ada hubungan antara pekerjaan orang tua dengan personal bygiene $(p>0,05)$.

\section{SARAN}

Perlunya pendidikan kesehatan berupa promosi kesehatan mengenai personal hygiene kepada para orang tua, khususnya ibu, untuk meningkatkan pengetahuan tentang personal hygiene .

\section{REFERENSI}

Akmal, S.C., Semiarty, R., dan Gayatri. (2013). Hubungan Personal Hygiene dengan Kejadian Skabies di Pondok Pendidikan Islam Darul Ulum, Palarik Air Pacah, Kecamatan Koto Tangah Padang Tahun 2013. Jurnal Kesehatan Andalas, 2(3): 164-167.

Arikan, I., Dibeklioglu, S.E., Arik, O., dan Gulcan, A. (2014). Personal Hygiene Status among Primary School Students in an Urban Area in the 
Jurnal Care Vol .5, No.3,Tahun 2017

west of Turkey. Amarican Journal of Research Communication, 2(7): 23-36.

Efendi, F, dan Makhfudli. (2009). Keperawatan Kesehatan Komunitas: Teori dan Praktik dalam Keperawatan. Jakarta: Salemba Medika.

Faridawati, Y. (2013). Hubungan Antara Personal bygiene dan Karakteristik Individu dengan Keluhan Gangguan Kulit pada Pemulung (Laskar Mandiri) di Kelurahan Sumur Batu Kecamatan Bantar Gebang Tabun 2013. Skripsi. Jakarta: UIN Syarif Hidayatullah.

Hassan, R., Alatas, H., Latief, A., Napitupulu, P.M., Pudjiadi, A., Ghazali, M.V., dan Putra, S.T. (2002). Buku Kuliab Ilmu Kesehatan Anak 1. Jakarta: Infomedika.

Hiola, R. (2012). Hubungan Antara Kebersihan Perorangan dan Pemakaian Alat Pelindung Diri dengan Kejadian Penyakit Kulit pada Petugas Pengelola Sampah di Tempat Pembuangan Akhir (TPA) Tanjung Kramat. Gorontalo: Universitas Negeri Gorontalo.

Indriastuti, P. (2009). Hubungan antara Pengetahuan Kesehatan Reproduksi dengan Perilaku Higienis pada remaja puteri. Surakarta: Universitas Muhammadiyah Surakarta.

Karim, Z., Arsin, A.A., dan Ansar, J. (2014). Hubungan Personal bygiene dengan Kejadian Demam Tifoid pada Anak di Puskesmas Galut. Makasar: Fakultas Kesehatan Masyarakat Universitas Hasanuddin.

Kusnin, R.M. (2015). Hubungan antara Personal bygiene dan Pemakaian Alat Pelindung Diri dengan Kejadian Penyakit Kulit pada Pemulung di TPA Tanjung Rejo Kecamatan Jekulo Kabupaten Kudus. Skripsi. Semarang: Universitas Negeri Semarang.

Notoatmodjo, S. (2010). Pendidikan dan Perilaku Kesehatan. Jakarta: Rineka Cipta.

Perry, A.G., dan Potter, P. (2010). Fundamental Keperawatan. Jakarta: Salemba Medika.

Ramadhan, K., dan Sabrina K.A, I. (2016). Hubungan Personal hygiene dengan Citra Tubuh pada Lansia di Desa Sepe Kecamatan Lage Kabupaten Poso. Jurnal Kesehatan Prima, 10(2): 1735-1748. 
Jurnal Care Vol .5, No.3,Tahun 2017

Sajida, A. (2012). Hubungan Personal bygiene dan Sanitasi Lingkungan dengan Keluban Penyakit Kulit di Kelurahan Denai Kecamatan Medan Denai Kota Medan Tahun 2012. Skripsi. Medan: USU.

Saryono. (2010). Catatan Kuliab Kebutuhan Dasar Manusia. Yogyakarta: Nuha Medika.

Sudarto. (1996). Penyakit-Penyakit Infeksi di Indonesia. Jakarta: Widya Medika.
Ummah, K., dan Lidiawati. (2015). Hubungan Personal hygiene dengan Tindakan Pencegahan Penularan Penyakit Kusta. Journals of Ners Community, 6(1): 92-99.

Yusiana, M.A., dan Saputri, M.S.T. (2016). Perilaku Personal hygiene Remaja Putri pada Saat Menstruasi. Jurnal STIKES, 9(1): 14-19. 